\section{Interim Project Results: \\ United Parcel Service's \\ Second-Generation Hybrid-Electric Delivery Vans}

As part of its commitment to reducing fuel use and emissions, the United Parcel Service (UPS) operates more than 2,500 natural gas, propane, electric, and hybrid-electric vehicles worldwide. The company uses these advanced vehicles as a "rolling laboratory" to learn how such technologies can best serve its large delivery fleet.

The U.S. Department of Energy's National Renewable Energy Laboratory (NREL) has a long history of helping UPS determine the impact of hybrid technology on fuel use, emissions, and operating costs. In 2008, NREL's Fleet Test and Evaluation Team evaluated the first generation of UPS' hybrid delivery vans, which demonstrated $29 \%-37 \%$ higher fuel economy than comparable conventional diesel vans. ${ }^{1}$

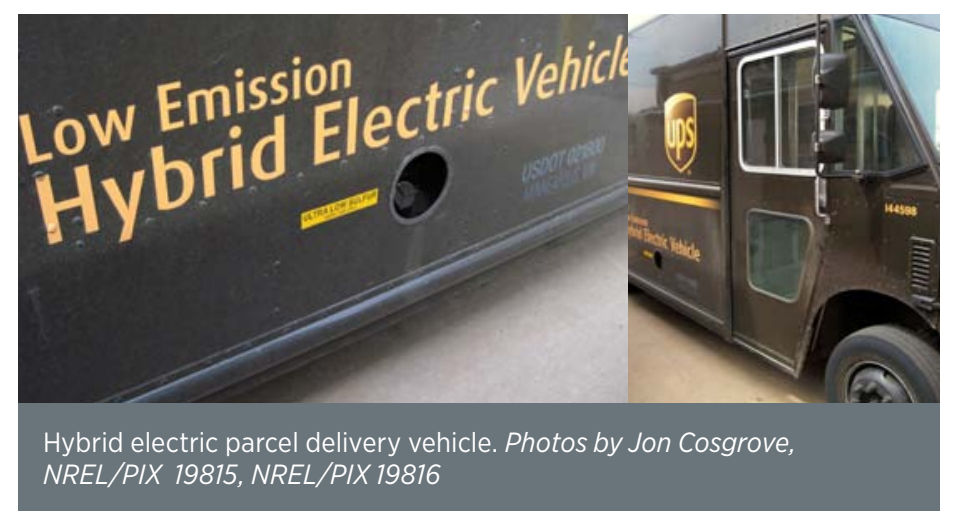

Encouraged by this success, UPS added 200 secondgeneration hybrid vans to its delivery fleet in 2010. These second-generation vehicles feature a new "engine off at idle" capability to further boost fuel economy. NREL's Fleet Test and Evaluation Team is in the process of evaluating the 18-month, in-service performance of 11 of these secondgeneration hybrid vans along with 11 comparable conventional diesel vans operating in Minneapolis, Minnesota.

As a complement to the ongoing field study, the team recently completed fuel economy and emissions testing at NREL's Renewable Fuels and Lubricants (ReFUEL) Laboratory.

\section{Vehicle Specifications}

The following table provides a side-by-side comparison of the second-generation hybrid vans and their conventional counterparts.

For results of the first-generation evaluation, see United Parcel Service Evaluates Hybrid Electric
Delivery Vans, National Renewable Energy Laboratory, 2010 (www.nrel.gov/docs/fy10osti/47327.pdf).

\begin{tabular}{|l|l|l|}
\hline Vehicle Specifications & \multicolumn{1}{|c|}{ Hybrid Electric } & \multicolumn{1}{|c|}{ Conventional Diesel } \\
\hline Van Manufacturer & Freightliner Corp. & Freightliner Corp. \\
\hline Van Model & P100H step van & P100D step van \\
\hline Van Model Year & 2010 & 2010 \\
\hline $\begin{array}{l}\text { Engine Manufacturer and } \\
\text { Model }\end{array}$ & $\begin{array}{l}\text { Cummins ISB 200 hp } \\
\text { MY 2009 }\end{array}$ & $\begin{array}{l}\text { Cummins ISB 200 hp } \\
\text { MY 2009 }\end{array}$ \\
\hline Emissions Equipment & DPF & DPF \\
\hline $\begin{array}{l}\text { Retarder/Regenerative } \\
\text { Braking }\end{array}$ & Regenerative braking & None \\
\hline Air Conditioning Type & None & None \\
\hline GVWR & $23,000 \mathrm{lbs}$ & $23,000 \mathrm{lbs}$ \\
\hline
\end{tabular}

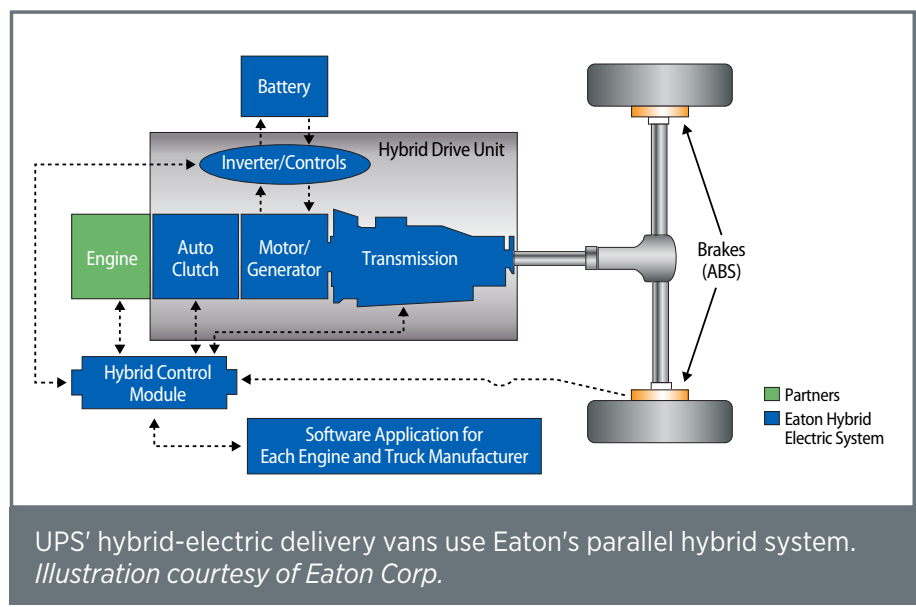

The hybrid vans are equipped with parallel hybrid systems manufactured by Eaton Corp., as displayed in the diagram above. These systems include a synchronous, brushless, permanent-magnet motor (26-kW continuous power and 44-kW peak power); regenerative braking (energy normally lost during braking is used to power the electric motor); and lithium-ion batteries (340 volts of direct current and $1.8 \mathrm{kWh}$ of energy storage).

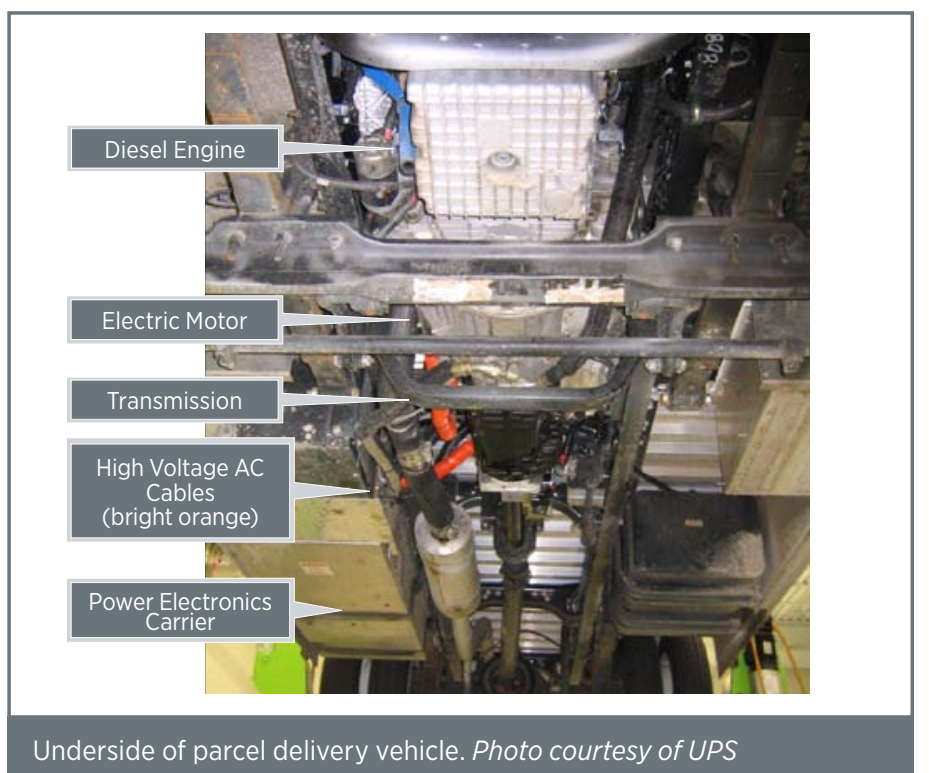




\section{Vehicle Testing in Laboratory}

Using the dynamometer at the ReFUEL Laboratory, the team tested one hybrid van and one conventional van on three standard drive cycles, selected based on in-use data collected by NREL.

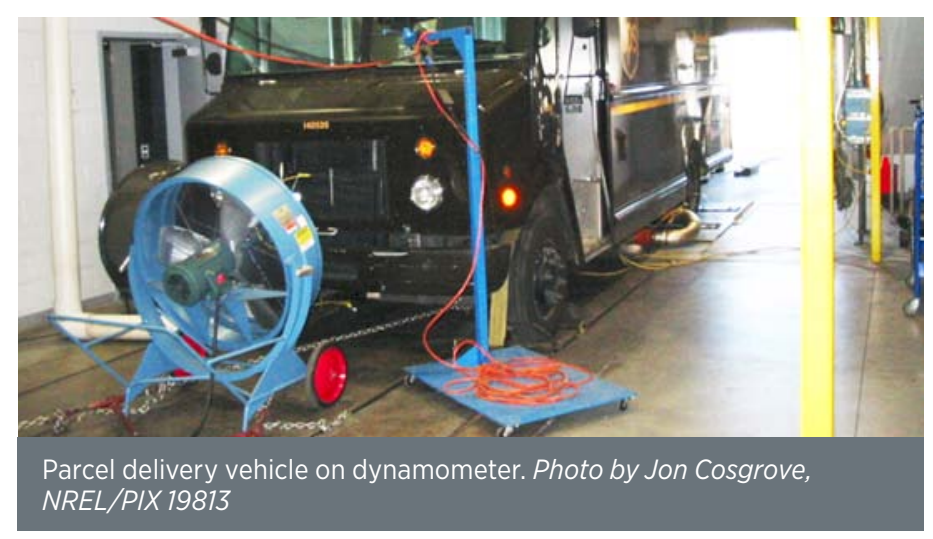

\begin{tabular}{|l|c|c|c|}
\hline Drive Cycle Statistics & NYC Comp & HTUF 4 & HHDDT \\
\hline Average Speed over Cycle (mph) & 8.8 & 12.1 & 26.0 \\
\hline Average Driving Speed (mph) & 13.1 & 22.5 & 35.6 \\
\hline Stops per Mile & 8.0 & 2.5 & 0.5 \\
\hline Aerodynamic Speed (ft/s) & 30.4 & 44.5 & 74.4 \\
\hline Characteristic Acceleration (dt/s/s) & -0.75 & -0.57 & -0.18 \\
\hline Kinetic Intensity (1/mile) & 4.30 & 1.51 & 0.17 \\
\hline
\end{tabular}

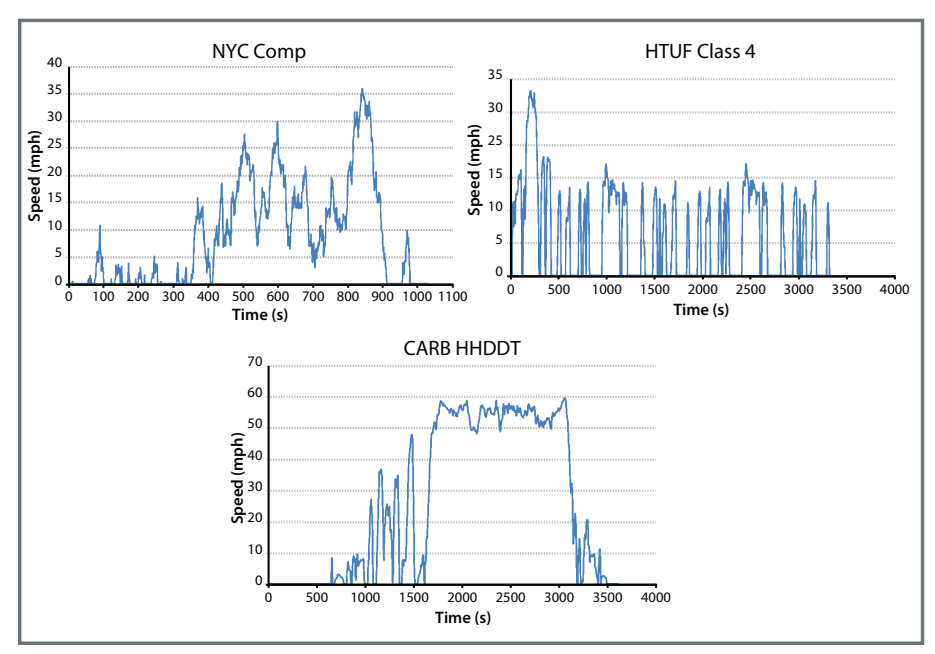

\section{Test Results}

Depending on the drive cycle, the hybrid van demonstrated a $21 \%-45 \%$ improvement in ton-mile/gallon fuel economy compared to the conventional van. These dynamometer test results represent statistically significant improvements at the 95\% confidence level.

\begin{tabular}{|l|c|c|c|}
\hline Ton Fuel Economy & NYC Comp & HTUF 4 & HHDDT \\
\hline Conventional P100D (ton-mi./gal) & 51.1 & 56.2 & 72.0 \\
\hline Hybrid P100H (ton-mi./gal) & 70.9 & 81.6 & 87.2 \\
\hline Hybrid Advantage (\%) & $39 \%$ & $45 \%$ & $21 \%$ \\
\hline Fuel Economy & NYC Comp & HTUF 4 & HHDDT \\
\hline Conventional P100D (mpg) & 6.8 & 7.5 & 9.6 \\
\hline Hybrid P100H (mpg) & 8.8 & 10.1 & 10.8 \\
\hline Hybrid Advantage (\%) & $29 \%$ & $36 \%$ & $13 \%$ \\
\hline
\end{tabular}

\section{Fuel Savings}

Extrapolating on these fuel economy results, the hybrid vans could save 0.7-2.4 gallons per day per van (or 176-610 gallons per year per van), depending on drive cycles and daily mileage. With the 11 hybrid vans in Minneapolis alone, UPS could reduce its diesel use by 1,900-6,700 gallons a year and save up to $\$ 23,000$ (at $\$ 3.43 /$ gallon) in fuel costs.

\begin{tabular}{|l|c|c|c|c|c|c|c|c|c|}
\hline \multicolumn{7}{c}{ Gallons Saved per Van Day of Operation } \\
\hline Miles per Day & 30 & 40 & 50 & 60 & 70 & 80 & 90 & 100 \\
\hline NYC Comp & 1.0 & 1.3 & 1.7 & & & & & \\
\hline HTUF 4 & 1.0 & 1.4 & 1.7 & 2.1 & 2.4 & & & \\
\hline HHDDT & & & & 0.7 & 0.8 & 0.9 & 1.9 & 1.2 \\
\hline & Gallons Saved per Van Year of Operation & & \\
\hline Miles per Day & 30 & 40 & 50 & 60 & 70 & 80 & 90 & 100 \\
\hline NYC Comp & 254.7 & 339.6 & 424.5 & & & & & \\
\hline HTUF 4 & 261.5 & 348.7 & 435.9 & 523.1 & 610.3 & & & \\
\hline HHDDT & & & & 176.4 & 205.8 & 235.2 & 264.6 & 294.0 \\
\hline
\end{tabular}

\section{More Results to Come}

Results-to-date are based on dynamometer testing at NREL's ReFUEL Laboratory. The ongoing field study will offer additional results, with a focus on in-use fuel economy, maintenance costs, operating costs, diesel particulate filter regeneration, and reliability of the hybrid vans compared to their conventional counterparts. These results will be detailed in an upcoming project report. For more information about this and other evaluation projects, visit NREL's Fleet Test and Evaluation website at www.nrel.gov/vehiclesandfuels/fleettest.

\section{Advanced Vehicle Testing}

This evaluation is part of a series of evaluations performed by NREL's Fleet Test and Evaluation Team with funding from the Advanced Vehicle Testing Activity (AVTA), which is managed by the U.S. Department of Energy's Office of Energy Efficiency and Renewable Energy (EERE). AVTA projects provide comprehensive, unbiased evaluations of advanced vehicle technologies in commercial use, enabling fleet owners and operators to make informed vehicle-purchasing decisions. All publications regarding the UPS hybrid delivery van evaluation are posted in the medium- and heavyduty vehicles section of the EERE website at www.eere.energy.gov/ vehiclesandfuels/avta.

This evaluation would not have been possible without the support and cooperation of many people. The authors wish to especially thank EERE and UPS.

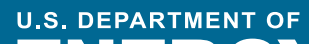
ENAROY

Energy Efficiency \& Renewable Energy
Printed with a renewable-source ink on paper containing at least $50 \%$ wastepaper, including $10 \%$ post consumer waste.
Prepared by the National Renewable Energy Laboratory (NREL), a national laboratory of the U.S. Department of Energy, Office of Energy Efficiency and Renewable Energy; NREL is operated by the Alliance for Sustainable Energy, LLC. 